\title{
RESPIRATORY PHYSIOTHERAPY IN PAEDIATRICS *
}

\author{
L. M. DAVIDS, B.Sc. (Physio) Witwatersrand, B.A. (Hons), U.O.F.S.. Dip. Ed. Physiother, Pret. $\dagger$
}

\section{SUMMARY}

The approach to respiratory physiotherapy followed at the Red Cross War Memorial Children's Hospital is described. An overview of therapy for the neonate, the child after surgery, the acutely ill child and the child attending the Physiotherapy Department as an outpatient, is given. Stress is laid on treatment of the child and not only his respiratory problem.

\section{INTRODUCTION}

When considering respiratory physiotherapy in paediatrics, it must be understood that one is not dealing with a scaled-down adult. One is dealing with a child who is developmentally, mentally and intellectually a totally different being from an adult. Also, one is not dealing with a child in isolation, but with a mother-child entity. For a child to reacl positively to treatment, one needs the help and cooperation of the mother. For a normal psychological response, the presence of the mother is essential in all children under the age of four years and helpful in the older child.

Any physiotherapist working with both in- and outpatient children will notice a marked difference in their behaviour. Outpatient children are less co-operative and protest much more. Most of the inpatient children are good. These socalled good children are not reacting normally. Respiratory physiotherapy is essentially a physical attack on the child and he should react vigorously to it. The inpatient child is being kept in an abnormal environment. Hospitalisation is an undesirable situation and should be resorted to only in the last instance. Hales-Tooke (1973) says "After seven months of age babies fret overtly in hospital, and up to the age of at least four years show signs of suffering as a result of separation from their mothers".

\section{RESPIRATORY PHYSIOTHERAPY FOR THE NEONATE}

The most frightening aspect of paediatric respiratory therapy is the treatment of the neonate. They are tiny and frequently it is the premature baby who requires chest treatment, viz the baby with respiratory distress syndrome (hyaline membrane disease).

At full term delivery the lungs are not fully developed. Terminal air sacs are shallow and wide necked and therefore patent, but there is a limited area for gas exchange. Lung growth continues with bronchiolar division and increases in number and size of the alveoli, thus increasing the area for gas exchange. The number of alveoli and airways increases ten times from birth to adulthood. Lung surface area increases twenty times. In the premature infant the lung is even more underdeveloped.

The upper respiratory tract is predisposed to obstruction. The nasal passages are narrow and the inf ant is an obligatory nasal breather for the first four weeks of his existence. The glottis and trachea are of small calibre and the relatively

* Lecture delivered to Hospital Group of the S.A.S.P. 19 September 1981.

$\dagger$ Principal Physiotherapist, Red Cross War Memorial Children's Hospital.

Received 17 February 1982.

\section{OPSOMMING}

Die benadering tot respiratoriese fisioterapie soos toegepas by die Rooikruis Oorlogsgedenkhospitaal vir Kinders word omskryf 'n Beskrywing van terapie vir die pasgebore baba, die kind na chirurgie, die kind wat ernstig siek is en die kind wat as buite-pasiënt die Fisioterapie Departement besoek, word gegee. Die behandeling van die kind en nie net sy respiratoriese roestand nie, w'ord beklemtoon.

large tongue can easily obstruct respiration. Thus any oedema of the larynx or trachea can easily cause an obstruction. Decrease in the size of the lumen will cause an increase in airway resistance.

The diaphragm is the most important muscle of respiration in the newborn. There is virtually no costah element to respiration. The ribs are horizontal so there is no bucket handle motion. The relatively large volume of abdominal contents with distension of the gastro-intestinal tract can readily compromise diaphragmatic action. When respiration is compromised. intercostal, subcostal and sternal retractions are evident because of the compliant cartilaginous thoracic wall.

These are some of the principal structural differences which demand adaptation of physiotherapy techniques. As the child grows the difference in techniques between child and adult diminishes.

The most common conditions which might require respiratory physiotherapy in the neonate are:

- Respiratory distress syndrome

- Tracheo-oesophageal fistula

- Neonatal tetanus

- Pneumonia (often caused by aspiration of milk)

It is not possible to discuss treatment regimens for any specific condition, but some adaptations will be detailed.

The fingertips are used for percussion in an intubated infant. Care must be taken not to shift the tube with too vigorous application. Percussion can cause breakdown of the anastomosis in a tracheo-oesophageal fistula with an end-to-end anastomosis. This type of case is suitable for the application of an electric toothbrush. If manual vibrationk used care must be taken not to squeeze the thoracic wall too hard because fractures may be caused.

The treatment session should be kept short because the infants tire quickly and easily become distressed. One must watch for recession. tachypnoea and mottling. Bagsqueezing is used when treating an intubated baby. At the end of a treatment session one may bag to help raise the $\mathrm{PaO}_{2}$ If secretions are thick and cannot be suctioned easily, saline can be used to thin them. This is administered $0.5 \mathrm{ml}$ at a time. The diameter of the suctioning catheter should be about $50 \%$ of the diameter of the tube because suctioning could collapse the immature alveoli, especially in the case of respiratory distress syndrome.

If the infant is not intubated, oral suctioning should be used as nasal suctioning of a neonate can be dangerous, especially if he has a nasogastric tube in situ. If both nostrils are blocked the infant cannot breathe. Oral suctioning of a baby with a repair of a tracheo-oesophageal fistula, who is not intubated, can cause damage to the anastomosis. The exact length of catheter that may be safely inserted must be ascertained from the surgeon. 


\section{RESPIRATORY PHYSIOTHERAPY IN THE ACUTELY ILL CHILD AFTER SURGERY}

Unless the child has undergone emergency surgery he should be treated pre- as well as post-operatively. It is very important to prepare the child psychologically as well as physically for an operation. The mother and the child should be prepared together. In the cardiac surgery unit the mother and child are taken to the unit and the apparatus is explained to the mother. Depending on the age of the child, everything is explained to him so that he knows what to expect.

One may have to clear the chest if the child is at all productive. He will be taught deep breathing and effective coughing. A sputum specimen is routinely taken. If the child is of an age that he can understand it, the whole postoperative physiotherapy routine is demonstrated on him. The techniques are similar to those used on an adult. To encourage deep breathing. an inspirometer may be used. Postural drainage is usually done in alternate side lying. If the child is too young to cough to command and to iexpectorate he may be suctioned orally, or nasally if he tends to vomit. If necessary, light tracheal pressure may be used to elicit an effective cough. When taking a sputum specimen, the cheeks are held to prevent the child from swallowing the secretions. Post-operatively the child may be intubated. He is given routine respiratory therapy such as alternate side lying with percussion, vibrations with bag-squeezing and use of saline if the secretions are thick or plugging. During treatment the percentage of oxygen administered may be increased to prevent too sharp a drop in the $\mathrm{PaO}$. The most common post-operative lung complications are right upper lobe atelectasis and left lower lobe collapse in the valve replacements.

If the child is not intubated, he must be suctioned if he coughs ineffectively. Tracheal pressure should not be used immediately post-operatively because of the danger of causing stridor. The child may be treated four times per day initially, depending on his condition. An uncomplicated post-operative course should not require therapy for longer than three to four days.

\section{RESPIRATORY PHYSIOTHERAPY IN THE ACUTELY ILL CHILD}

The most common respiratory conditions seen in the medical wards are pneumonia (viral, post-measles, staphylococcal, etc), paralysis of the muscles of respiration in Guillain-Barré syndrome, bronchiolitis, status asthmaticus and laryngo-tracheal bronchitis.

If oxygen therapy is required for an infant or small child, it is administered in a headbox. An oxygen monitor should be used with a headbox. When physiotherapy is given, the child should be treated under oxygen. Secretions are removed by oral and nasal suctioning.

The child with laryngo-tracheal bronchitis who requires a tracheostomy may become a long-term patient if extubation is unsuccessful. Portex tracheostomy tubes with connectors are used. Humidification is administered via a mask that fits over the connector. The infant is nursed on his back with his neck extended over a roll placed under the sheet. No pillows are allowed. There is thus little danger of the child flexing his neck and obstructing the tube. The baby is treated twice a day using percussion, vibrations and suctioning. The nurses also suction whenever necessary. Older children are given speaking tracheostomies if they are kept in hospital for any length of time. They may be treated daily or less frequently, depending on their condition.

When a child is extubated, he is kept quietly in bed for 2-3 hours before physiotherapy. Then the child is treated normally, suctioned orally and encouraged to cough. He is also suctioned via the stoma using a mucus aspirator to ascertain the amount of residual secretions. If the child is able to cough effectively and clear the secretions, he should remain extubated.

Long term tracheostomy leads to a developmental problem and any physiotherapist working with these patients should be aware of this. They often cannot be sent home and thus need a total care programme involving the parents if possible. While they are babies they need toys and the opportunity to move normally. As they mature they need more sophisticated play and as much everyday experience as possible i.e. play outside, sand, water, outings etc. Ideally they also need the same care-giver to ensure a stable upbringing.

\section{RESPIRATORY PHYSIOTHERAPY FOR THE CHILD IN THE OUTPATIENT DEPARTMENT}

In the outpatient department one most frequently sees pneumonia with collapse/consolidation and bronchiolitis. Effective treatment includes educaton of the mother. If the mother does not treat the child at home, therapy cannot be really successful. Postural drainage is done over pillows and a tiny baby can be drained on the lap. The child is percussed, vibrated and suctioned orally or nasally. Jacques catheters are used to prevent trauma to the mucosa. Older children are encouraged to cough and expectorate. Specimen jars make very useful disposable sputum mugs and the amount of sputum is easily measured. If the child coughs effectively and swallows the secretions he need not be suctioned. The mother is taught to percuss and drain the child; if the child does not cough on percussion the mother may be given some catheters and be taught how to stimulate a cough. With some of the older, profoundly retarded children with cerebral palsy, one may teach the mother how to apply tracheal pressure. Postural drainage can be done at home over an upside-down chair with pillows on it. Great stress is laid on the importance of the mother treating the child twice a day.

\section{THE CHILD WITH CHRONIC RESPIRATORY DISEASE}

For any physiotherapist dealing with paediatric respiratory cases, the child with chronic respiratory disease, such as extensive, inoperable bronchiectasis or fibrocystic disease, can be the most difficult to handle. The treatment consists of postural drainage in all positions, percussion, vibration, possible nebulisation and effective coughing. Therapy is aimed at keeping the chest clear and preventing acute chest infections. The mother again is the key figure in the treatment of these children. She needs constant support from the doctors and physiotherapists and she must understand the importance of routinely treating the child whether he is well or ill.

As soon as cystic fibrosis is diagnosed the mother is sent to the Physiotherapy Department to be taught postural drainage and percussion. Babies are positioned over pillows in side lying on alternate sides and are also positioned in sitting. The mother is taught to percuss each area for 3-5 minutes and the child is treated twice a day before meals. The mother is taught how to stimulate a cough with a Jacques catheter if the child is at all productive. As the child grows older, she must teach him to cough effectively and expectorate. Depending on the child, he will cough to command at about $2 \frac{1}{2}$ years of age and be able to expectorate properly at about $31 / 2$ years. The mother is later taught to vibrate the chest, but as the child grows the purchase of a mechanical vibrator is encouraged. This is 
especially useful when the child complains of pain on percussion. When the child requires regular nebulisation with a mucolytic agent (Mistabron 2:2 ml saline), the parents will need a compressor unit which can be adapted for disposable nebulisers. As the child grows, pillows become less useful for postural drainage and the purchase of a foam wedge is advised.

Respiratory physiotherapy must become a part of the child's normal daily routine. Advice about games and sport is also given. Thus the child needs to attend the Physiotherapy Department only when he has an acute chest infection, but the parents know that they can come at any time for advice and/or treatment.

\section{CONCLUSION}

Some aspects of respiratory physiotherapy in children have been touched on. The techniques used on adults are also used on children, but adapted for the size and condition of the patient. It must be understood that the child is in the process of developing and in order to treat him with maximum effectiveness, his stage of physical, intellectual and emotional development should form the basis of the therapeutic approach.

\section{References}

Hales-Tooke, A. (1973). Children in hospital - the parents' view. Priory Press, London.

Levin, R. M. (1976). Paediatric respiratory intensive care handbook. Medical Examination Pub. Co. Flushing, N.Y. Robertson, J. (1977). Young children in hospital. 2nd ed. Tavistock. London.

Smith, C. A. ed. (1977). The critically ill child, diagnosis and management. 2 nd ed. W. B. Saunders. Philadelphia. 